5 Goodwin, H. B. (1923). The Coutinho method for zenith distance and the Ball altitude tables, Naut. Mag., 1 10, 294.

6 Ball, F. (1 907). Altitude or Position-Line Tables, London.

7 Goodwin, H. B. (1924). The Coutinho method for position lines practically tested at sea, Naut. Mag., 111 , 188.

\title{
Collision Avoidance Systems
}

\author{
J. Watt \\ (Marconi Communication Systems)
}

I was sorry to have missed the two papers by Captain K. D. Jones and Mr P. J. Houseley on the above subject, presented at a recent meeting of the Institute, and the subsequent discussion. Fortunately both Captain Jones and Mr. Houseley have been kind enough to let me see copies of their papers and I would like to add two pieces of information which may be of interest with reference to Captain Jones's paper.

The first is in regard to the making of 'the first decision' in clear weather. Captain Jones says that most mariners on sighting a target decide on the risk, or the probable miss distance, by an accurate even if intuitive evaluation of aspect and range. (They must also take into account the relative bearing of the target and its speed relative to that of own ship.) For the purposes of his argument Captain Jones omits from the clear weather case the alternative method of using radar in assessing the risk or probable miss distance. Evidence on the comparative accuracies of these two methods may be of interest; a series of demonstration runs on the Predictor automatic plotting radar in Elettra III in the English Channel provided an opportunity to obtain some such evidence.

On one occasion which I have in mind, under conditions of clear visibility in daylight, a ship estimated at about 2000 tons was seen about $45^{\circ}$ off the port bow at a (radar) range of 7 miles in a crossing situation. A consensus of five or six practising mariners, on board for the demonstration, visually inspected the ship and said that it would pass well clear ahead. Meanwhile the radar was maintaining an automatic 4-plot 6 minute track which, when switched to Relative Track mode and extrapolated by cursor, indicated a close passing ahead of within one quarter mile, i.e. within 0.15 inch on the CRT screen. The consensus declared that the miss distance would be much greater and that the radar was wrong. So the situation was allowed to develop. The extrapolated 4-plot relative track stuck consistently to its indication of a miss distance of something under a quarter of a mile ahead, and in due course the target crossed our bows at about two cables distance.

The visual assessment at 7 miles range was made using unaided human eyesight and human judgment, to work out a problem in space and time to which eyesight and judgment are not very well suited. The radar on the other hand in presenting a compass stabilized plot of the relative motion of the target, which required for its accuracy no knowledge of the target's aspect nor any assumptions concerning the speed of either vessel, and which only needed to be extrapolated to show the bearing and distance of CPA, was doing the job it does best. 
The above suggests that the visual assessment of risk made on first sighting a target in clear weather will not always be correct; yet we know that collisions due to this cause are so rare as to be negligible. The reason must be that in clear weather any failure to recognize a close passing situation on first sighting will only cause the development of a closer quarter situation than expected and, as is well known, any danger of collision arising in a close quarter situation in clear visibility is much more easily manœuvred out of than in fog. An important factor here is the comparative immediacy with which the fact that a ship is altering can be seen from its changing aspect.

The point remains that, even if the radar sensor could establish aspect at one look as effectively as the human eye in clear weather, this would not displace, say, a 6-minute compass stabilized relative track as an early, and progressively more accurate, indicator of CPA.

My other comment regarding Captain Jones's paper is simply to point out that an automatic plotting radar with a prediction (trial steering) facility can be used to help in making the ' 3 rd decision', i.e. the safest time to resume the voyage after an alteration has been made to avoid risk of collision. Thus if an alteration has been made from an original course of say $090^{\circ}$ to $120^{\circ}$, to pass astern of a ship closing on the starboard bow on a course approximately at right angles to that of own ship, the proposed new course control can be set back to the original course of $090^{\circ}$ as soon as, or even before, own ship has settled on the avoiding course. With the radar in its Predicted Relative Tracks mode the positive contribution due to own ship's progress on $120^{\circ}$ can then be seen building up and, when the predicted CPA distance has increased sufficiently to ensure that the target will not be alarmed when own ship turns back on to $090^{\circ}$, the alteration back to original course can safely be made. If resumption at this time would create conflict with some other ship this would be seen and appropriate action taken.

To assist in the extrapolation of the 4-plot actual relative tracks, or relative tracks predicted for a proposed alteration, a rotatable cursor inscribed with parallel lines is fitted on the Predictor radar, as Mr. Houseley says, and can be used for greater accuracy, rather than extrapolation by eye if the apparent or planned passing distance is going to be small. Mr. Houseley says that a mechanical cursor above the face of the display is not a very accurate device. I do not condone inaccuracy but would contend that the parallel line cursor, provided that it is used with the care to which the radar observer is accustomed, introduces negligible inaccuracy. I presume Mr. Houseley is thinking of parallax and the like, but the Predictor display system has the advantage that the 4-plot tracks it displays are made up from the actual radar data, up-dated every io seconds so that any fluctuating errors, for example the aerial bore sight errors or gyro-compass errors he describes, can be seen by the user and averaged out, or appreciated as giving a bracket of values of CPA distance. By its nature, Predictor cannot present a clear, confident track based on inadequate or false data; it is fail-safe.

Repeating that I do not condone inaccuracy, I would query what degree of accuracy is operationally essential. If, using equipment like Predictor under conditions of reduced visibility, the extrapolated 4-plot relative track of a target at seven or eight miles range is seen to indicate a miss distance of one quarter or one half mile, the prudent officer-of-the-watch even though he feels that he can see exactly how the situation is developing will not assume that his opposite number in the target vessel is doing or can do likewise (as he could fairly safely 
assume in clear weather). He will therefore take the seamanlike precaution of reducing the risk by a reduction in speed or by a course alteration before a close quarter situation has had a chance to develop. Likewise when danger threatens and he uses the trial steering facility, to pre-test the effect of a contemplated collision avoidance alteration, he will not plan to produce a CPA distance which is still so small that the new situation created by his alteration may not be clearly seen to be safe by the ship to which he is giving way. Such an action would introduce the risk of that ship being caused mistakenly to mancuvre in an unforeseeable manner when the resultant close quarter situation was being reached. Admittedly it is not always possible to manœuvre to increase the CPA distance as much as one would like, but we do not recommend that Predictor's trial course facility be used to plan close shaves.

\section{Four-Point Mooring}

\section{Lt.-Commander K. G. Lees, R.N.}

H.M.S. Reclaim was built in 1948 by Simons \& Co. of Renfrew as a salvage ship of the King Salvor class but altered before completion for her role as a deep diving vessel. She established world deep diving records in 1948 ( $53^{6} \mathrm{ft}$., $163 \mathrm{~m}$.) in Loch Fyne, the diver wearing a standard diving dress and breathing a mixture of oxygen and helium, and in $1956(600 \mathrm{ft}$., $183 \mathrm{~m}$.) off Norway. In 1964 she carried out a series of dives to $600 \mathrm{ft}$. for one hour, off Toulon, the divers wearing lightweight self-contained equipment. In 1950 she located the sunk submarine Truculent in the Thames estuary and in 1964 the submarine Affray, when underwater television was used for the first time. In 1966 she recovered a crashed Viscount aircraft in the Irish Sea. Reclaim is now engaged in trials which will eventually permit diving for prolonged periods to $1000 \mathrm{ft}$., and therefore anywhere on the Continental Shelf.

Two divers are lowered to the sea-bed in a submersible compression chamber equipped with underwater lighting and television and in telephonic communication with the ship. While one diver swims out of the chamber to undertake the required task the other acts as attendant. The chamber when hoisted aboard under pressure is locked on to another chamber in the ship's hold, where the divers carry out the process of decompression which may take several hours.

H.M.S. Reclaim encounters some unique navigation and seamanship problems when engaged in deep diving. To place the divers on a particular job the ship has to be held stationary above the position; and this is accomplished by carrying out a four-point moor whereby the ship is anchored by each bow and quarter. In order to moor in this way Reclaim is fitted with two $2 \frac{1}{2}$-ton bower anchors each connected to fifteen I 5 -fathom shackles of $1 \frac{1}{2}$ in. chain cable; on the stern are carried two $1 \frac{1}{2}$-ton Danforth anchors each connected to 270 fathoms of 5 in. wire. The disparity between the weight of the anchors and cable forward and the anchors and wire aft means that more wire has to be let out aft than cable forward. This equipment enables the ship to be moored in depths of water down to $600 \mathrm{ft}$. 